\title{
Franz Faupel Named JMR Associate Editor in Europe
}

Franz Faupel of the University of Kiel, Germany, has been appointed associate editor in Europe for the Journal of Materials Research. He replaces Heinrich Wollenberger of the Hahn Meitner Institute, who recently retired after six years of service to JMR. Faupel will oversee editorial decisions for all papers submitted for review to the European office.

Faupel received his diploma and $\mathrm{PhD}$ degree in physics from the University of Göttingen in 1982 and 1985, respectively, working on diffusion and defects in metals and alloys. In 1987, he joined the IBM T.J. Watson Research Center in Yorktown Heights, N.Y., as a postdoctoral fellow, studying mechanical properties of metal-polymer structures as well as diffusion and solid-state reactions in thin films. In 1988, he returned to the University of Göttingen, where his research focused on diffusion in amorphous media, the formation of metal-polymer interfaces, and thermodynamics, particularly of hightemperature superconductors.

Since 1994, Faupel has been a full professor and is the chair for multicomponent materials within the faculty of materials science and engineering at the University of Kiel, where he is also a faculty member in the Physics Department. At Kiel, he is continuing his research on metal-polymer

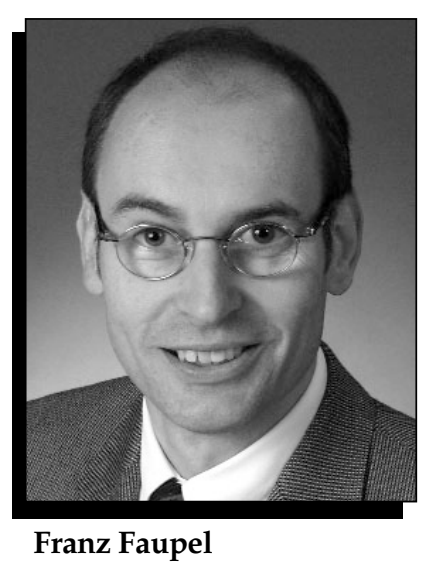

interfaces, mainly related to their structure and formation, interfacial chemistry, and adhesion. His additional interests include the preparation of organic thin films and novel metal-polymer nanocomposites for functional applications by gas-phase deposition, as well as the investigation of defects and diffusion in crystalline and amorphous metallic alloys, supercooled liquids, and polymers. He has published more than 120 research papers and has participated in international joint research projects.

Since 2000, Faupel has been chair of the metal physics division of the German
Physical Society (DPG), and before that, he was chair of their joint working group on metal physics (AG Metallphysik). In addition to being an active MRS member, he is a member of the German Materials Research Society (DGM) and the German Society for Metallurgy (VdEH). Faupel serves on the editorial boards of Applied Physics Letters and the Journal of Applied Physics and is a member of the editorial advisory boards of Defect and Diffusion Forum and the Journal of Adhesion Science and Technology.

Gordon E. Pike, editor-in-chief of JMR, said, "I am delighted to have such a talented, active, and enthusiastic associate editor. I am confident that Professor Faupel will continue Professor Wollenberger's efforts to increase the journal's manuscript flow and quality."

To have a manuscript considered by the associate editor in Europe, authors are asked to submit the manuscript through JMR's online submission system and include a note in the "Comments to Editor-in-Chief" section, stating that they would like the paper to be reviewed by the European office. Submission instructions and a link to the submission site can be found on the JMR Web site at www.mrs.org/publications/jmr. MाR]s 